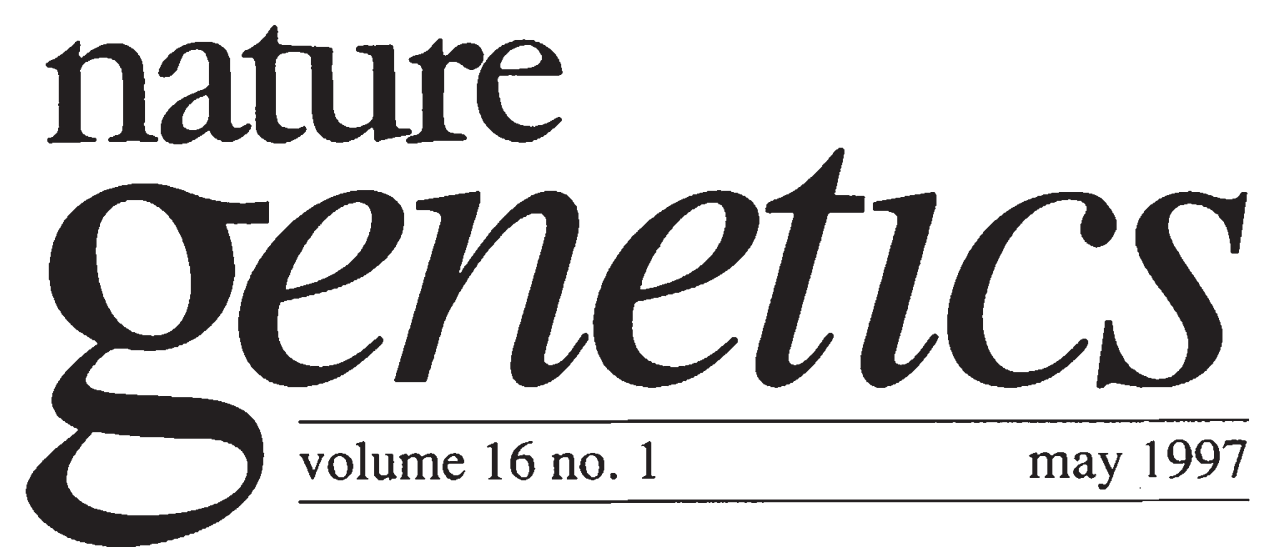

\title{
One for the vine
}

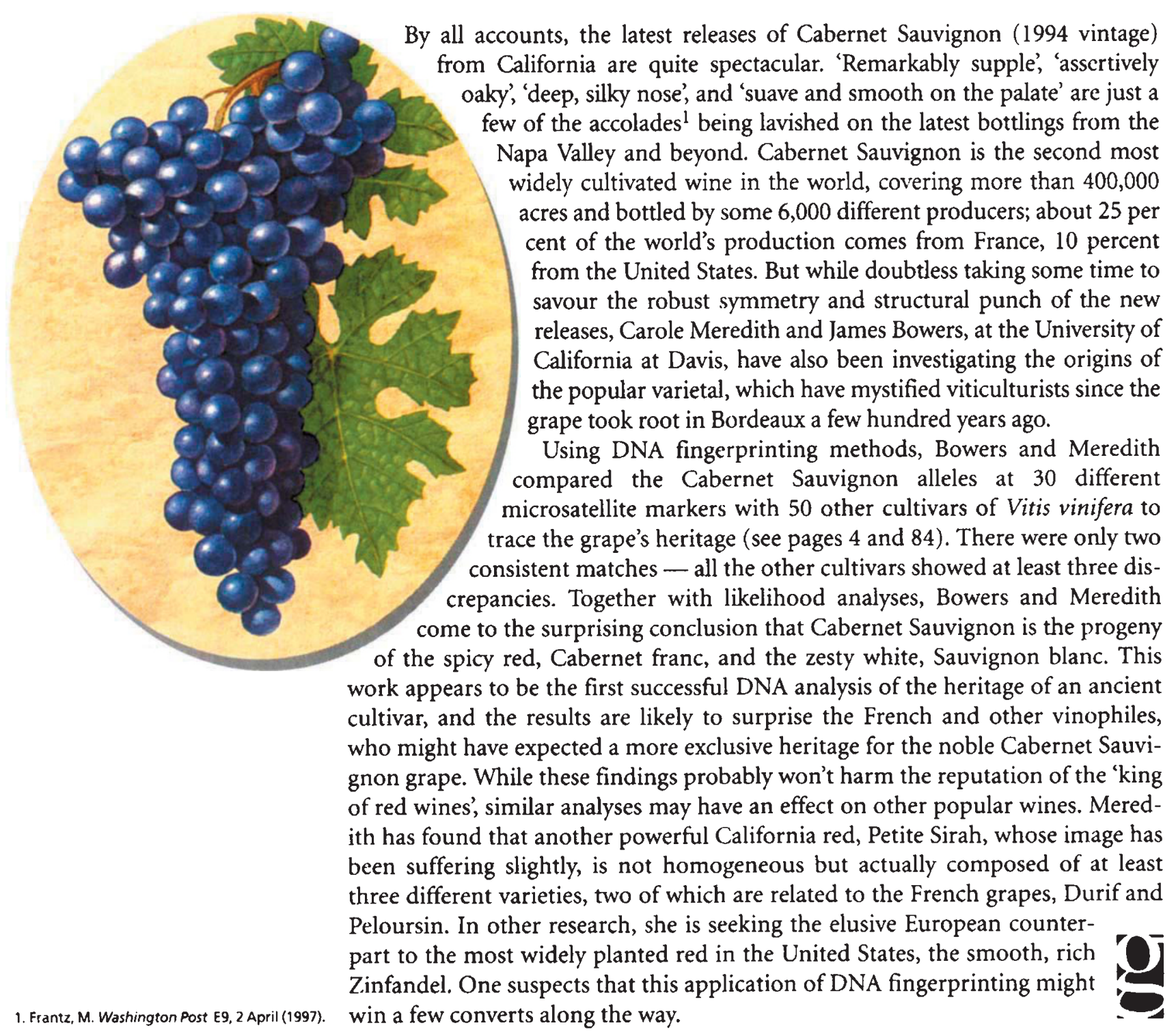

